\title{
Impact of size and distribution of installed PV power in E-W direction on the level in which selected consumers' energy needs were met
}

\author{
Krzysztof $\mathrm{Necka}^{1,{ }^{*}, \text { Hubert Latala }}{ }^{1}$, Stawomir Kurpaska ${ }^{1}$, Jarosław Knaga ${ }^{1}$, Anna Karbowniczak ${ }^{1}$ \\ ${ }^{1}$ Faculty of Production and Power Engineering, University of Agriculture in Krakow, Poland,
}

\begin{abstract}
The aim of the study was to analyse the energy needs of selected consumers and to select the PV installed capacity in the east and west panels orientation (E-W). The analysis was carried out for two variants. The first concerned the impact of the installation power of a PV source on the contracted power in its symmetric east and west position. The second variant was the result of previous observations and studies of the authors of this paper. Thus, in this variant, the unbalanced power of PV E-W in relation to the $\mathrm{S}$ azimuth has been analyzed, taking into account the characteristics of the recipients' needs and the variation of the PV power installed. The analyses show that an increase in meeting the energy demand for two of the tested plants at symmetrical power distribution to the east and west occurred only when the installed power was increased to the level of approx. 1.4-1.6 of the contracted power. However, the power distribution in the E-W direction has a very strong effect on the energy amount that is generated in the power plant and cannot be used due to the lack of demand in the plant.
\end{abstract}

\section{Introduction}

In the recent years we could have observed a dynamic increase of the power installed in the renewable energy sources. At the end of 2016 the capacity of RES installations holding a licence of the Energy Regulatory Office achieved the level of over $8.4 \mathrm{GW}$ and the systems using the wind energy (5.8 GW) and biomass $(1.3 \mathrm{GW})$ had the largest share therein.) [1]. Whereas the highest growth dynamics of the installed power was present in the installations using solar radiation. Within the period of three years the capacity of such installations increased from nearly $2 \mathrm{MW}$ in 2013 to over $99 \mathrm{MW}$ in 2016. Moreover, at the end of 201617 thousand of PV systems connected to the network based on declaration were operating with the total capacity of $100[1,2]$ MW. Further growth in the installed power of such systems is very likely due to the decreasing investment expenditures and support system financed with many sources.

Nevertheless, photovoltaic installations constitute an energy source with a highly dynamic change both in the twenty-four-hour, as well as in the annual period. The level of the generated power mostly depends on the incident radiation, the value of which is variable in time. Thus the activities aimed at the increase in the level of adjusting the energy demand of a plant to its availability from the local PV system are targeted [3, 4].

Increase in the simultaneity of occurrence of energy demand and its availability may be implemented through modification of an hourly energy demand profile or the use of a modified solar energy profile depending on orientation of the PV panels [5,6]. The first of the methods for optimisation of the use of the available energy is limited to a large extent by the necessity of execution of a specific technological process in a plant. In plants that have already been operating it may be very often used to a limited scope or may require large financial expenditures for modernisation of the existing infrastructure. On the other hand, such types of activities bring excellent results if they are implemented as early as at the stage of design of the given facility. In the course of selection of a photovoltaic power station for an existing plant, for which we know the hourly energy demand profile activities, in which the required capacity of photovoltaic panels will be installed with different azimuth, may turn out to be intentional.

Many research teams have dealt with the problem of selection of the optimum orientation and tilt angle of mono- and polycrystalline photovoltaic panels and allowing specific features at the place of location of the installation [7 - 11]. According to such tests the tilt angle of the reception plane of modules depends on the place of location, season and day of the year and meteorological conditions. In all the analysed cases the use of systems for tracking the apparent movement of the sun enabled the growth of the energy yield from a PV installation from several to several dozens percent.

However, micro PV power plants with tracking systems are expensive and may not always be used from

Corresponding author: krzysztof.necka@ur.krakow.pl 
a technical point of view $[5,12]$. Therefore, for many applications the only solution which aims at the increase of the level in which the demand is met from a PV system may be construction of a stationary installation with power distribution for different reception plane orientations. In such situation the maximum energy production may be obtained on the condition that the tilt angles value and azimuth for a specific application are optimally set.

\section{Materials and methods}

Information for implementation of the study regarding the amount of the available solar radiation has been obtained based on the long-term meteorological data available on the websites of the Ministry of Infrastructure and Construction for the place of location of the investigated facilities. The characteristics with regard to the distribution of solar radiation were limited to surfaces inclined under the angle of $30^{\circ}$ to the horizontal plane. The analyses considered the availability of energy with the level enabling operation of the CIGS panels. Its permitted limits were specified based on the previous authors' own study which provides that operation of thin-film panels begins when the incident radiation exceeds $50 \mathrm{~W} \cdot \mathrm{m}^{-2}$ and is present until its value decreases below $40 \mathrm{~W} \cdot \mathrm{m}^{-2}$.

The second source of information comprised the results of the authors' own study carried out at the photovoltaic power plant situated at the Faculty of Production and Power Engineering, University of Agriculture in Krakow, Poland. The conducted research concerned the operation of thin-film modules of CIGS type with the power capacity of $230 \mathrm{Wp}$ in a configuration enabling acquisition of information on energy production for panels oriented to the east (1.54 $\mathrm{kWp})$, south $(4.4 \mathrm{kWp})$ and west $(1.54 \mathrm{kWp})$. The energy yield for the specific azimuths of operation was designated in relation to the value of power installed in specific module chains.

The study also used the information on energy consumption of the selected recipients, from which hourly energy demand profiles were developed. Three recipients were selected to the analysis, characterised by a different profile of energy needs, i.e. a dairy cooperative, drinking water intake station and wastewater treatment plant.

The next stage was to specify the way in which the size of the installed power and azimuth of the reception surface of the cells influences the cooperation of the power station with a recipient characterised by the specific energy demand profile. During the study the impact of the change in the power station capacity was analysed within the range of 20 up to $200 \%$ of the contracted power, as well as power distribution in the E$\mathrm{W}$ direction. The size designated for a power station with contracted power of a plant and south azimuth was adopted as a point of reference. Due to the amount of the energy available from solar radiation the study was limited to the period with the best solar conditions i.e. the months of June, July and August.
In order to assess the use of the energy generated in a photovoltaic power station a coefficient for meeting the energy demand of a recipient $\left(V_{p z}\right)$ was defined, as well as a coefficient for surplus energy acquired from a PV power station $\left(V_{n e}\right)$, which specifies the amount of energy produced, but not used by a recipient due to lack of demand in a given period. The use and surplus energy coefficients were defined with the change in the power station capacity for four separately analysed orientations of PV panels arrangement.

$$
\begin{aligned}
& V_{p z(E, S, W, E-W)}=\frac{E_{p v(E, S, W, E-W)}-E_{n(E, S, W, E-W)}}{E_{c}} \cdot 100 \% \\
& V_{n e(E, S, W, E-W)}=\frac{E_{n(E, S, W, E-W)}}{E_{p v(E, S, W, E-W)}} \cdot 100 \%
\end{aligned}
$$

where:

$E_{c}$ - energy consumption in the facility,

$E_{P V(E, S, W, E-W)}$ - energy produced in the PV power station for orientation accordingly in the east (E), south (S) and west (W), and with the arrangement of panels in the east and west position (E-W),

$E_{n(E, S, W, E-W)}$ - surplus energy produced in the PV power station for orientation accordingly in the east (E), south $(\mathrm{S})$ and west $(\mathrm{W})$, and with the arrangement of panels in the east and west position (E-W).

\section{Results and discussion}

The annual availability of solar radiation enabling the operation of PV installations designated based on typical meteorological years for Krakow depending on the orientation of a PV module changes from $989 \mathrm{kWh} \cdot \mathrm{m}^{-2}$ in $\mathrm{W}$ direction, through $997 \mathrm{kWh} \cdot \mathrm{m}^{-2}$ for $\mathrm{E}$ direction up to $1118 \mathrm{kWh} \cdot \mathrm{m}^{-2}$ for $\mathrm{S}$ direction. The efficiency of operation of a PV power station is influenced not only by the annual availability of solar radiation, but also by its intensity. The conversion efficiency of solar radiation depends to a large extent on the incident radiation. The rated power specified in photovoltaic panels is most often designated in STC or NOCT conditions, in which it is assumed that incident radiation amounts to 1000 and $800 \mathrm{~W} \cdot \mathrm{m}^{-2}$ accordingly. The conducted research shows that the availability of solar radiation at hourly intervals for the averaged meteorological year at the place of location of a power plant may achieve as much as 1200 $\mathrm{Wh} \cdot \mathrm{m}^{-2}$, but the period of its occurrence is very short. In the district of Krakow the most often available energy has a value of its flux up to $200 \mathrm{Wh} \cdot \mathrm{m}^{-2}$ and the share of hours for which the available solar radiation exceeds 800 $\mathrm{Wh} \cdot \mathrm{m}^{-2}$ amounts to less than $3 \%$.

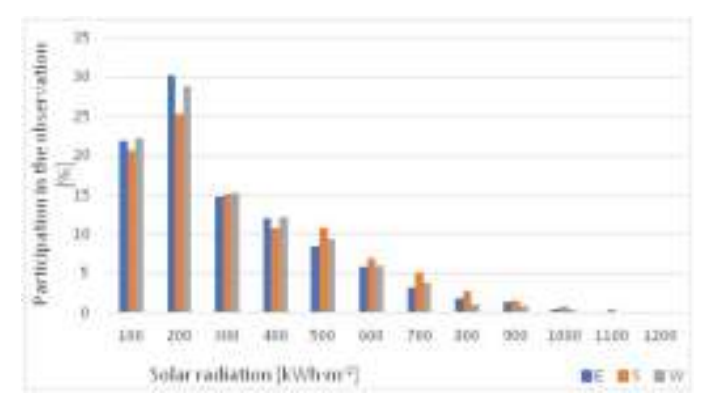


Fig. 1. Histogram of hourly availability of solar radiation depending on panel orientation in annual period

In order to cover the energy demand for a recipient characterised by a specific energy demand profile it is important that solar radiation (Fig. 2) coexists with energy demand (Fig. 3).

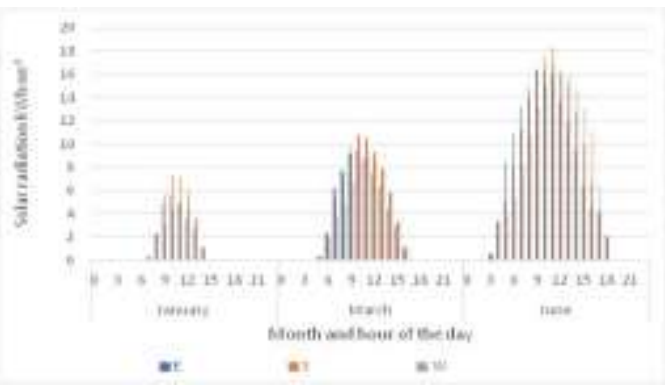

Fig. 2. Averaged distribution of hourly availability of solar radiation in characteristic months with a value allowing for operation of power station depending on orientation of PV module plane

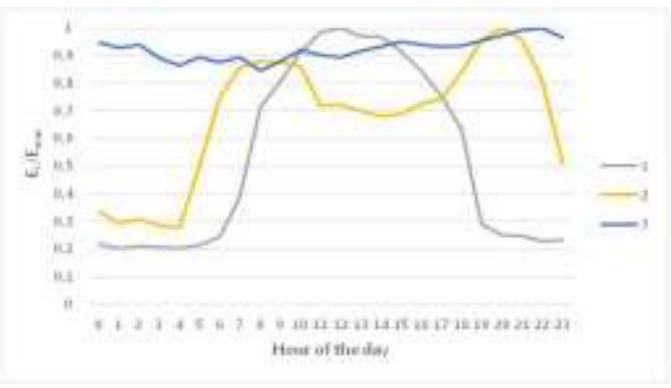

Fig. 3. Reduced energy demand profiles for: 1) District Dairy Cooperative, 2) drinking water intake station, 3) wastewater treatment plant

where:

$E_{i}$ - energy consumption at a given hour of the day,

$E_{\max }-$ maximum hourly energy consumption on a given day

The subsequent part of the study presents the test results for three recipients of electrical energy characterised by different energy demand profiles (Fig. 3 ). In the course of research the influence of the installed power of the PV power station and the ratio of arrangement of panels in the E-W direction on the level in which energy demand is met, as well as its amount generated the PV power station, but not used by the plant were analysed.

The first part of the research verifies the way in which the change in the installed power of the PV power station in relation to the contracted power of the plant will influence the level in which the demand for electrical energy is met and the amount of the generated surplus energy that the plant did not use. The power of the photovoltaic power station was changed in the range from $20 \%$ to $200 \%$ of the contracted power. Figures 4 and 5 show the results of the obtained tests. a) Plant 1

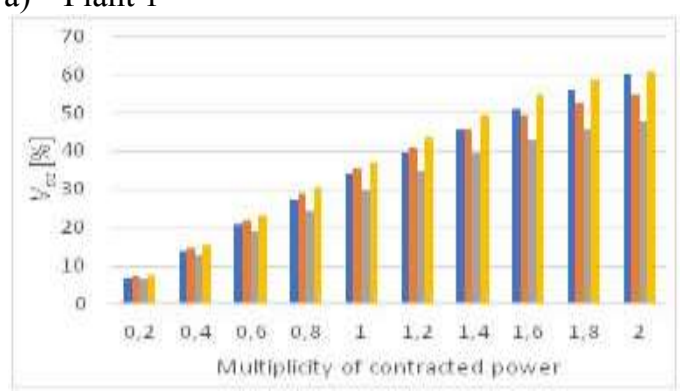

b) Plant 2

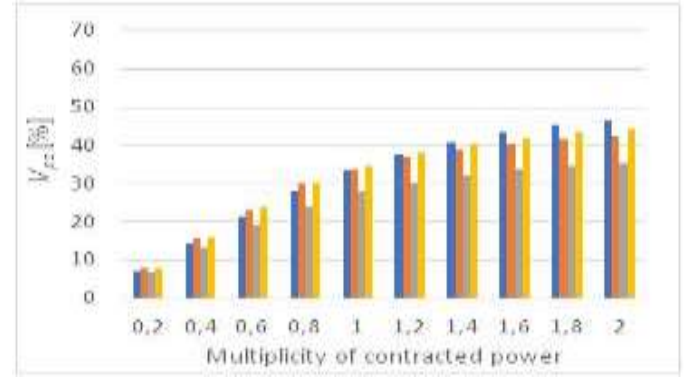

c) Plant 3

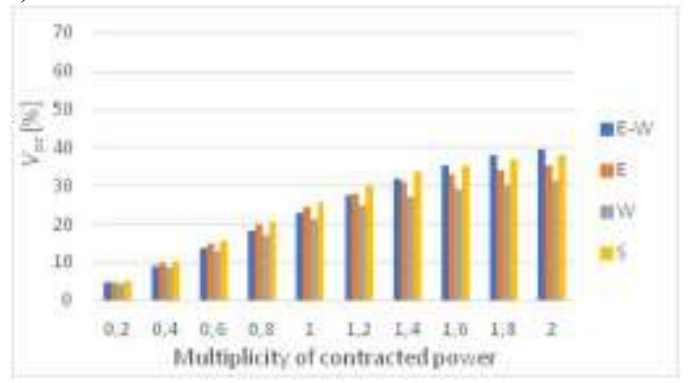

Fig.4. Impact of power of PV power station and panel orientation on the level in which energy demand is met for specific recipients.

The conducted analyses prove that the energy demand will be met to the lowest extent for all the facilities with the $\mathrm{W}$ direction panel orientation, regardless the power station capacity. Decrease in the level in which demand is met in relation to the $\mathrm{S}$ direction was in the range between 16 and $22 \%$. The change of the orientation in the E direction also did not bring an increase in the level in which the demand was met in relation to the south, and its drop was reduced and fluctuated in the range from 2 to $10 \%$. Only after symmetric distribution of the power in the E-W direction the increase in the level in which the energy demand is met was obtained for plant 2 and 3 (drinking water intake station and wastewater treatment plant), provided that the power station will be over-dimensioned in relation to the contracted power by at least $40-60 \%$. The observed increase in the satisfaction level of the energy demand of a facility from a renewable energy source amounted to $4-5 \%$ with doubled efficiency of the installation capacity. However, the analysis of differences between the average twenty-hour satisfaction of the energy demand performed in Statistica program after a change in the azimuth from the south (S) to east- 
west position (E-W) did not indicate statistically significant differences at the significance level of $\mathrm{p}=$ 0.05 .

a) Plant 1

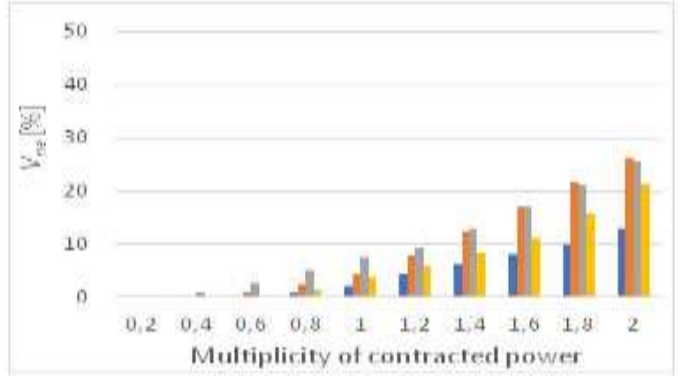

b) Plant 2

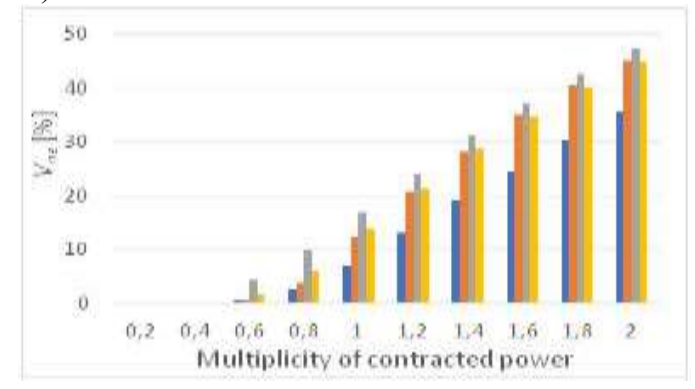

c) Plant 3

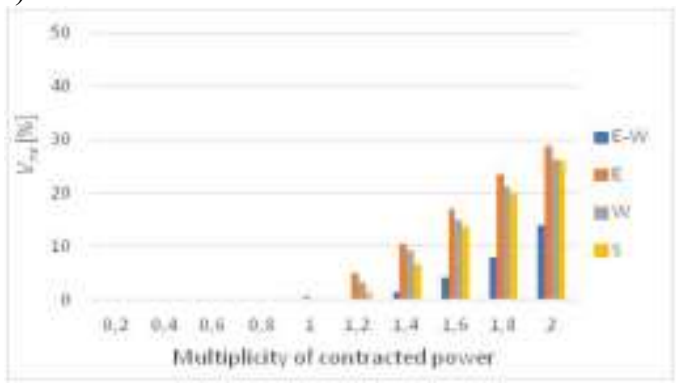

Fig.5. Impact of power of PV power station and panel orientation on the amount of energy that was produced in PV power station, but not used due to lack of demand at the given period for specific recipients

The suggested changes in the capacity of PV installation and the method of installation of panels had a large influence on the level of matching the demand and availability of the generated electrical energy. The performed analyses show that the best solution for the investigated recipients due to minimisation of the surplus of the generated energy is construction of a power station with symmetrically distributed power in the E-W direction. Such a solution enabled the reduction of the share of unused energy by ca. $10 \%$. Alternative solutions consisting in panel orientation only in the $\mathrm{E}$ or $\mathrm{W}$ direction caused the increase in the amount of unused energy towards the south azimuth. However, the essential changes from the point of view of statistics occurred for the adopted significance level in the amount of surplus energy only for the plant number 3 .

In the further part of the study tests results are presented, in which the impact of distribution of the power installed in the specific directions $(\mathrm{E}-\mathrm{W})$ on the level in which the energy demand is met and the share of the produced, but unused energy was analysed. The study limited the analysis to two variants of capacity of a PV power station. The first one was equal to the contracted power of the plant, and the second one was $60 \%$ higher. Oversizing the power station results from the previous analysis, in which the prevalence of the satisfaction level for a power station with power distributed in the E-W direction in relation to $\mathrm{S}$ was observed from this point.

According to the conducted simulations for the first plant where the peak energy demand is present from 10 a.m. to 2 p.m. due to the level in which the energy demand is covered, it is the most favourable to arrange the panels in the $\mathrm{S}$ direction, regardless the power station capacity. For the other two plants the most favourable solution of power distribution depends on its amount. In case of the installation power equal to the contracted power in the drinking water intake station, the increase in the level in which the energy demand is covered at the level of $0.7 \%$ was observed for power distribution in the $\mathrm{E}$ direction $80 \%$ and $\mathrm{E} 70 \%$ in relation to the reference level which comprised the level of satisfaction of the demand with orientation in the $\mathrm{S}$ direction. In the third plant, the highest level in which the demand was covered was obtained for positioning in the S direction. After the capacity of the PV power station increased by $60 \%$ in the second plant, the highest increase of nearly $3 \%$ was obtained with the installation of $50-60 \%$ of power in $\mathrm{E}$ direction. An insignificant growth was observed for the last plant $(0.7 \%)$ with the share of power in the $E$ direction amounting to $60 \%$. Nevertheless, the differences observed in all the analysed cases were too small to be statistically significant for the adopted significance level.

a) Plant 1

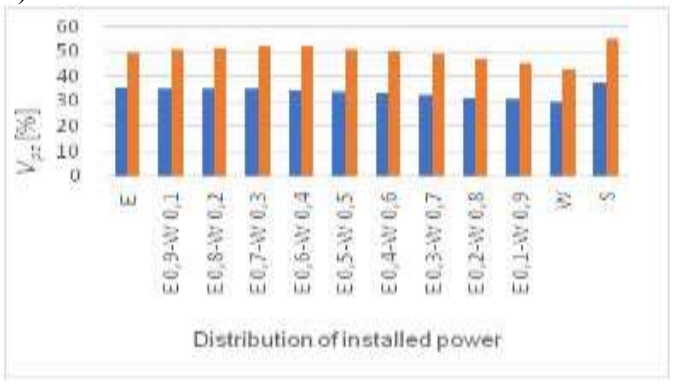

b) Plant 2

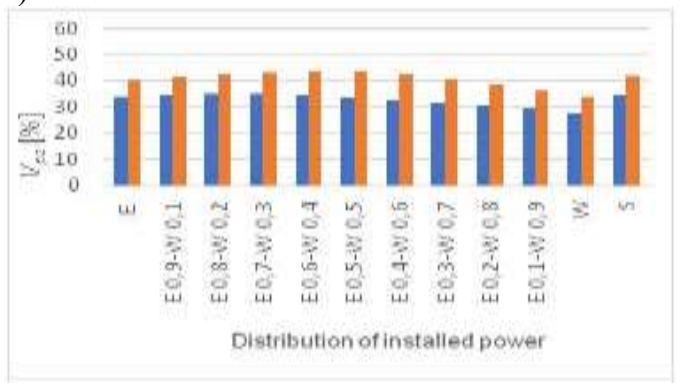


c) Plant 3

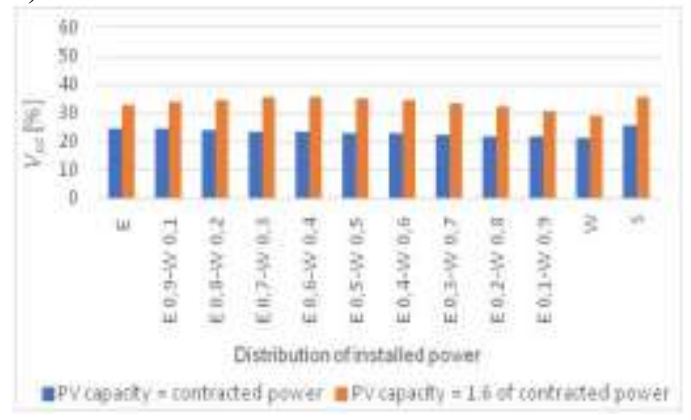

Fig. 6. Impact of power distribution of PV power station in the direction $\mathrm{E}, \mathrm{S}, \mathrm{W}$ on the level in which energy demand was covered for the specific recipients

The share of energy that the tested facilities could not use for all the plants depended on the capacity of a PV power station. In the first facility the surplus energy achieved a low level of nearly 2 and $8 \%$ accordingly for the rated power and $60 \%$ of oversizing with the power distribution in the $\mathrm{E}$ direction amounting to $60 \%$. For the second plant the highest consumption of the produced energy was also registered with $60 \%$ of power installed in the $\mathrm{E}$ direction and power station capacity equal to contracted power of the plant, and after its oversizing, for symmetric distribution to the specific directions. In case of the last plant the surplus energy occurred only after the increase in the power station capacity and their lowest value was characterised by symmetric power distribution. The differences observed between surplus energy for the south azimuth (S) and after optimal power distribution to the east and west (E-W) for all the analysed cases were sufficiently high so as to assume that they are significantly different from the adopted significance level.

a) Plant 1

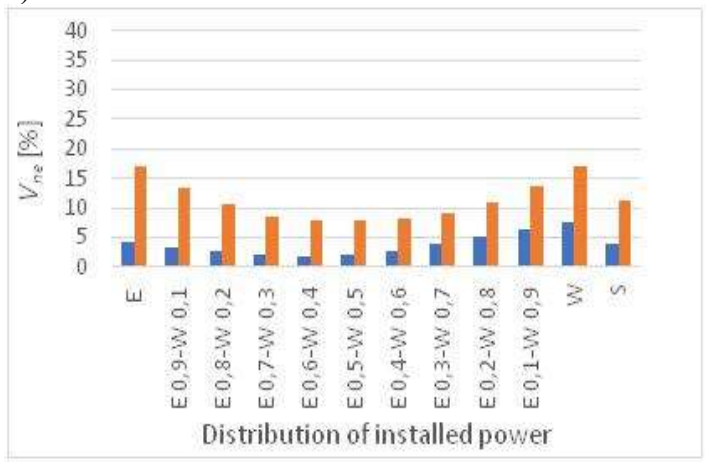

b) Plant 2

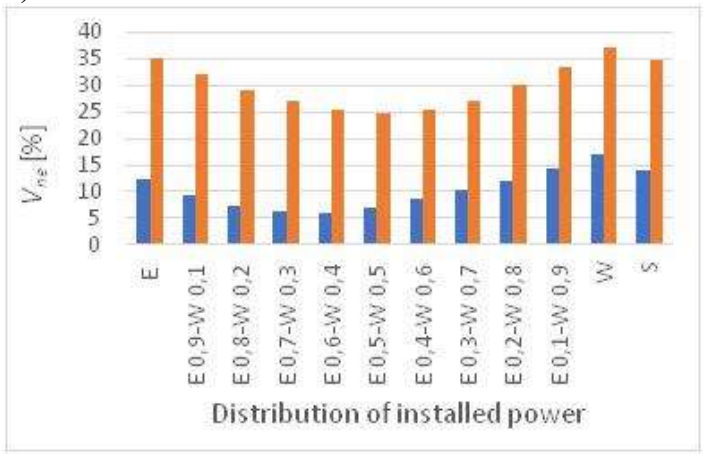

c) Plant 3

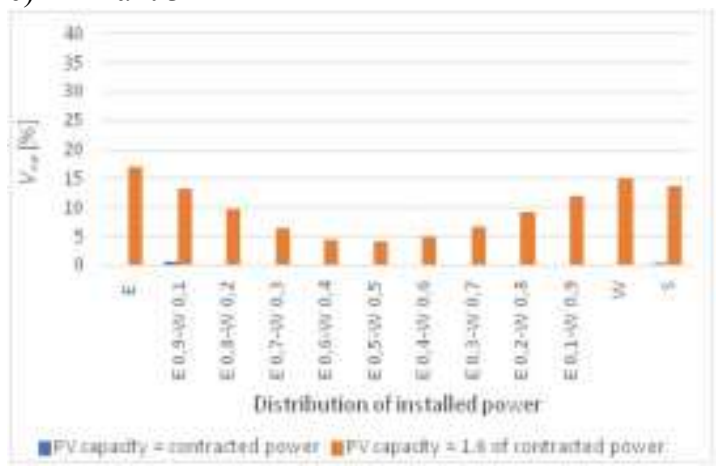

Fig.7. Impact of power distribution of PV power station on the amount of energy produced in PV power station, but unused due to lack of demand at the given time for the specific recipients

\section{Conclusions}

On the territory of Małopolska Voivodeship $45 \div 50 \%$ of solar radiation has a value of energy flux below 200 $\mathrm{W} \cdot \mathrm{m}^{-2}$, and nearly $3 \%$ of solar radiation approaches the level in which the rated power of PV modules is specified.

The performed analyses show that both the size, as well as distribution of the installed PV power in the E-W direction influences the level in which the energy demand is met and the amount of surplus energy from PV for the selected recipients in a different manner.

Installation of panels only in the $\mathrm{E}$ or $\mathrm{W}$ direction caused deterioration of cooperation of the power station with the tested facilities. An insignificant increase (4$5 \%$ ) of the demand satisfaction level was observed for the drinking water intake station and wastewater treatment plant after symmetric power distribution to the $\mathrm{E}$ and $\mathrm{W}$ and a simultaneous increase of the power station capacity by $40 \div 60 \%$ in relation to the contracted power of the plants. The advantage of such power distribution is the increase in matching the profile of available solar radiation to the profile of energy demand in plants.

The conducted analysis of test results showed that the best solution for the studied recipients due to minimization of the surplus of the produced energy is construction of a power station with power distributed symmetrically in the E-W direction. Such a solution enabled reduction of the share of the unused energy by approx. $10 \%$. On the other hand, alternative solutions consisting in panel orientation in the $\mathrm{E}$ or $\mathrm{W}$ direction lead to a negative phenomenon of increase in the amount of unused energy with regard to the south azimuth.

The increase in use of the available solar radiation up to $3 \%$ was also obtained by changing the ratio of distribution of the installed power in the $\mathrm{E}$ and $\mathrm{W}$ direction. Such distribution of the installed power of the PV power plant had the greatest impact on the drinking water intake station, the energy demand profile of which is characterised by clear bimodality. 
This research was financed by the Ministry of Science and Higher Education of the Republic of Poland

\section{References}

1. Urząd Regulacji Energetyki. https://www.ure.gov.pl/pl/rynki-energii/energiaelektryczna/odnawialne-zrodla-ener/potencjalkrajowy-oze/5753,Moc-zainstalowana-MW.html. (2017)

2. Rynek fotowoltaiki w Polsce. Instytut Energetyki Odnawialnej (2017)

3. T. Szul, J. Knaga, K. Nęcka, TEKA Komisji Motoryzacji i Energetyki Rolnictwa, vol. 13, nr 2, 91-96, (2013)

4. J. Knaga, K. Nęcka, Logistyka, 5, 199-206. (2015)

5. Bugała, G. Frydrychowicz-Jastrzębska, Poznań University of Technology Academic Journals no 79 Electrical Engineering. 47-54. (2014)

6. P. Sawicka-Chudy, M. Cholewa, M. Sibiński, R. Pawełek, Przegląd Elektrotechniczny ISSN 00332097, R. 92 NR 9. 58-61. (2016) doi:10.15199/48.2016.09.15

7. H.M.S. Hussein, G.E. Ahmad, .H.H. El-Ghetany, Energy Conversion and Management, Volume 45, Issues 15-16. 2441-2452 (2004), https://doi.org/10.1016/j.enconman.2003.11.013

8. E. Mehleri, P. Zervas, H. Sarimveis, J. Palyvos, N. Markatos, Renew. Energy, 35, 2468-2475, (2010)

9. J. Rakovec, D. Kastelec, K. Zakšek, K. Brecl, M. Topic. Orientation and Tilt Dependence of a Fixed PV Array Energy Yield Based on Measurements of Solar Energy and Ground Albedo-a Case Study of Slovenia. INTECH Open Access Publisher (2011)

10. J. Kaldellis, D. Zafirakis, Energy, 38, 305-314. (2012)

11. A.K. Yadav, S.S. Chandel. Renew. Sustain. Energy Rev., 23, 503-513. (2013)

12. K. Oprzędkiewicz, J. Teneta, Automatyka. Tom 15. Zeszyt 2. 381-388, (2011) 